\title{
Natural Resource Potential as a Factor in the Formation of the Region's Natural-Economic System
}

\author{
Naylya Amirova ${ }^{1}$, Lyudmila Sargina ${ }^{1}$, and Asiya Khasanova $^{1}$ \\ ${ }^{1}$ Plekhanov Russian University of Economics, Academic Departments of Political Economy \\ and of the History of Economic Science, 117997, Moscow, 36 Stremyanny lane, Russia
}

\begin{abstract}
The need to deepen theoretical research on the reproduction of regional natural-economic systems, the mechanism of their economic transformation and the development of methodological foundations for further improving the development of the region is one of the basic issues in the implementation of the strategy for sustainable development, determining the most effective directions for solving environmental management and environmental protection problems. The processes of transformation of natural-economic systems of a regional level are caused, first, by factors that contribute to the transfer of part of the reserves of natural resources into the natural-resource potential of the regions. Thus, the development of scientific and technological progress contributes to the reduction of current and investment costs for the extraction and processing of natural resources in the context of new technical capabilities. The role of the latter is also high in solving the problem of exceeding the growth rate of the use of natural resources in comparison with their reproduction and restoration. The rationalization of the use of reserves of natural resources, which is justified by the ever-increasing needs of society, necessitates the economic assessment of different gradation of natural resources in terms of quantitative and qualitative analysis. In this regard, the article attempts to find an answer to a number of questions about the content, object, mechanism of development of the natural-economic system based on the natural resource potential of the region.
\end{abstract}

\section{Introduction}

The economic transformation of the natural-economic system based on the natural resource potential should be considered as the next stage of the system's movement. It is based on the process of reproduction, determined by the interaction of natural resources and the productive forces of the region. The content of the development of the regional natural-economic system based on the natural resource potential is the process of discrete adjustment of its functional state. Thus, the economic system enters the regime of unstable dynamic equilibrium, which ensures its evolution process [1-2]. In this regard, the determining attribute of the new configuration of the interaction of the natural economic system and the natural and resource potential of the region is the analysis of the movement of the system in the unity of 
reproduction and development of the natural and economic space, the use of the natural resource potential and socio-economic development of the region.

\section{Materials and Methods}

The concept of the article is based on an understanding of the process of greening the region's natural-economic system in line with the development of the theory of rational environmental management. The formation and specialization of the natural resource potential of regional economic complexes are one of the basic issues in the implementation of the strategy of sustainable development of the regions, determining the most effective directions for solving the problems of rational environmental management and environmental protection. The presence and potential of natural resources in the region determines the distribution of productive forces in a given territory, forms its specialization and determines its place in the territorial division of labor. Along with this, what will be the content and pace of regional development depends on the conditions of production and the specificity of the use of natural resources.

There are a number of factors that contribute to the transfer of part of the reserves of natural resources into the natural resource potential of the regions. Thus, the development of scientific and technological progress contributes to the reduction of current and investment costs of natural resources extraction and processing in the context of new technical capabilities. The role of the latter is also high in solving the problem of exceeding the growth rate of the use of natural resources in comparison with their reproduction and restoration. The rationale for the extraction and primary processing of natural resources should be carried out in the conditions of the functioning of effective market mechanisms through "demand-price" regulator and the tax system.

The rationalization of the use of reserves of natural resources, which is justified by the ever-increasing needs of society, necessitates the economic evaluation of different gradation of natural resources in terms of quantitative and qualitative parameters [4-6]. Assessment of the natural resource potential should be based on the determination of the value of the available resources of nature, the damage resulting from inefficient use of natural resources, as well as the effectiveness and environmental safety criteria for using both the entire potential of natural resources and its individual components. It is worth pointing out some aspects that the assessment of the potential of natural resources does not fully take into account: the use of one and the same resource in different fields of activity, the possibility of interaction between nature objects, the presence of different options for the intensity of use and application of technologies with respect to the resource used within the framework of one kind of activity.

The powerful and diverse potential of Russia's natural resources, which allows us to provide the necessary volumes of domestic consumption and export, has a number of features that are characterized as large-scale and complex.

A special place in the natural resource potential of Russia is occupied by mineral resources (about 20 thousand deposits), the huge reserves of which provide the country with a certain role in the global economy. Thus, more than 55 trillion rubles is the total value of all mineral energy resources (oil, gas, iron ore, coal, gold, copper, diamonds), which amounted to $60 \%$ of GDP in 2017 . Of these, about three quarters of recoverable value and estimated reserves are in oil, gas and coal. In ensuring the national economic and defense security, mineral resources, being the resource base of industrial potential, also occupy a special place. However, only $10 \%$ of deposits account for $60 \%$ of all explored mineral resources, but $30 \%$ of the mineral deposits put into commercial development provide half of the extraction of mineral raw materials. 
The continuous growth in the use of minerals in the national economy determines the allocation of the most important direction of the technical policy of mining industry, which is based on the integrated and rational use of mineral resources. So, the additional involvement of 5 million tons of steel, 1 million tons of oil, about 5 million cubic meters of gas in the process of economic activity is equivalent to saving the corresponding mineral raw materials by only $1 \%$, which will significantly reduce material costs in the national economy.

The most large-scale processes of development, extraction of mineral resources, in particular fuel, energy carriers and metals, can be observed in Siberia, where the backbone factor of the regional economy is the development of coal production and the metallurgical complex, which includes mining and enrichment of raw materials to the stage of finished products in the form of ferrous and non-ferrous metals, as well as their alloys.

The formation of the base of ferrous metallurgy in Siberia began in the Soviet period, which today remains the youngest metallurgical base in Russia. Thus, about one fifth of the total iron production in Russia is carried out on the basis of such enterprises as the Kuznetsk and West Siberian metallurgical plants and the Novokuznetsk Ferroalloy Plant. Mining enterprises operating in the Kuzbass region, in Mountain Shoria, Khakassia (Western Siberia) and the Korshunovsky ore enriching plant in Eastern Siberia, use iron ore raw materials as their basis for their activities. The launch of an enrichment plant in the Kemerovo Region, which is based on the production of manganese ore concentrate, which is a necessary component of ferrosilicon manganese production, will allow the West Siberian Metallurgical Plant to use raw materials mined in the region. The production of ferrosilicon manganese, which is a raw material for the smelting of high-quality steel grades, will significantly reduce the cost of metal and increase its competitiveness.

One of the indicators of scientific and technological development of any country is the volumes of extraction, production and consumption of rare metals, the fundamental components of technological innovations in nuclear, electronic and military equipment, highquality optics, as well as the machinery [5]. The use of rare-earth metals in high-tech industries has contributed to a steady trend towards an increase in market demand from 5 to 125 thousand tons per year over the past five decades, where the main demand is generated by technologically advanced countries: China (54\%), Japan and South Korea (24\%), the countries of Europe and the USA (respectively $13 \%$ and $8 \%$ ).

The first place in the reserves of rare-earth metals is held by China, which share is more than $47 \%$. That allows the country to control up to $95 \%$ of the world market for this segment. Along with this, the CIS and the USA are characterized by relatively high shares $-16 \%$ and $11 \%$, respectively. As for Russia, the country imports almost all the necessary amount of rare-earth metals [3].

It should be noted that the balance reserves of rare-earth metals allow Russia to take second place after China. The reserves of these metals in Russia are concentrated in 16 deposits, in particular, in the Lovozersky loparite deposit, Tomtor deposit and the Khibiny group of apatite ore deposits. Siberia also has large volumes of explored reserves of rareearth ore, but the low level of high-tech types of production in the country and the underdeveloped consumption infrastructure determine the lack of interest in mining this type of subsoils. Thus, the demand on the domestic market for rare-earth metals is characterized in the amount of $2-3 \%$ of annual world consumption and is generated only by the state corporation Rostech and enterprises of the military-industrial complex. The lack of development of intermediate redistribution enterprises leads to the fact that insignificant production volumes of the Lovozero deposit are fully exported.

The situation on the world market of mineral resources, in particular, rare-earth metals, Russia's dependence on imports of these metals, and the technical lag of high-tech industries necessitates improving the national economic security through the rational use of mineral resources based on integrated mining and processing of the national natural resources. 
The natural resource potential includes, among other things, land resources, which play a significant role in the economy of any country because, first, it is an object of land relations. Land resources are a means of production, territory for the organization of production, an object of long-term investments, and the living environment of the country's population. The variety of uses necessitates their classification according to various criteria. Thus, according to the Land Code of the Russian Federation (art. 7), agricultural land is allocated for its intended purpose; Industrial, Energy, Transport, Radio, Television, Informatics, Space, Defence, Security and Other Special Land; earth of settlements; lands especially protected areas and objects; earth of water fund; Forest fund land and stock land.

In the post-reform period, a redistribution of the land fund took place in Russia. The country has about 220 million hectares of land suitable for agricultural production. However, a significant part of agricultural land was abandoned and, thus, withdrawn from the reproductive process. This has become one of the most negative phenomena: unused land occupies more than $16 \%$ of agricultural land (including $16.7 \%$ of the total area of arable land) [1]. To some extent, this can be explained by economic disadvantage in that part where it was caused by excessive plowing of land in certain regions (especially northern) or changes in production conditions for agricultural production and the possibility of selling products. But still, the main reason for such a modern state of land resources is the result of the prevailing bias of the formed agricultural land market, when agricultural land is acquired as an object for investment without the intention of using it for its intended purpose, but solely for their subsequent resale (when the price of land rises) or for its subsequent development.

At the present stage, when the task of import substitution in the field of food production is actively being implemented and the task of entering domestic agricultural producers on the world market as exporters is being solved, the problem of returning abandoned agricultural land to economic circulation is becoming even more relevant [1]. The legal aspect of solving this problem was created by the relevant legal documents that provide for the removal of land from agricultural use when they are not used for their intended purpose or used in violation of the laws. The economic aspect is expressed in the fact that the land passes to a more efficient owner, using it for its intended purpose. The link connecting the legal and economic aspects of solving the problem is the state, which in this case is expressed through organizational and managerial mechanisms to influence the situation. First of all, for this it is necessary to fully apply all measures provided for by existing legislation. In particular, to use differential taxation on land depending on its use: for the actual use of agricultural land for its intended purpose, a reduced tax rate (not more than 0.3 percent of the cadastral value) is provided; if land is not used, then the general rate applies. Using the achievements of the digital economy, it is necessary to create a civilized land management system for decisionmaking in the interests of effective landowners and land users. This will help create an open transparent market for the sale and lease of agricultural land.

The competitive advantage of Siberia is the availability of a powerful land resource. However, for various reasons of an all-Russian and regional nature, land as the most important national wealth, the main means of production in agriculture, is not always used rationally and effectively here. Today, in the subjects of the Siberian Federal District, reliable information on the quantitative and qualitative state of the land fund has actually been lost. This problem requires its urgent solution in order to use them more efficiently. The integrated use of the entire land fund of the region contributes to the rational development of the agroindustrial complex and rural territories of Siberia, allows not only to produce food, but also to diversify production. Almost $70 \%$ of the territory is occupied by forest land, which contributes to the active development of the organic products market, which is based on the collection of wild berries, fruits, medicinal and aromatic plants, mushrooms, nuts, etc. The Siberian region has natural reservoirs, which are the largest sources of electricity in country, 
transport routes, and above all, the natural resources of water supply. A variety of climatic conditions here allows the development of cold-water and warm-water fishing.

The Kemerovo region, as one of the largest territorial-and-production complexes in Russia, which is based on the coal industry and power producing, is characterized by the withdrawal of highly productive agricultural land for industrial use with the further formation of technologically-disturbed complexes in their place. This process is a rather acute problem for the region, characterized by significant dynamics and an unfavorable environmental situation. The development of agricultural production in the Kemerovo region is facilitated by a combination of such factors as a leveled topography, agro-climatic conditions, and soil resources. The region is characterized by uneven use of agricultural land: plowed land is $49 \%$ in the central, steppe and forest-steppe regions; about 35\% in the northern part; in the mountains $-9 \%$. About half of the Kemerovo region is unsuitable for agricultural use. There is an all-Russian tendency to reduce agricultural land. Difficult geological conditions for the location of seams contribute to the high intensity of the development and production of coal deposits, and thus, this regional feature contributes to a large loss of agricultural land. It has been established that 1 million tons of coal mined by the underground method is accompanied by the loss of 20-30 ha of farmland, by the open method -116.2 ha with an annual alienation of up to 78 thousand ha [4]. Therefore, based on the challenges of increasing the size of raw material extraction, it can be assumed that the process of transformation of natural landscapes into technogenic complexes will only increase, and the area of disturbed lands will increase. Thus, the rational and efficient use of land resources is the basis of economic growth and the basis for ensuring the economic security of the regions and the country as a whole.

In other words, a necessary condition for the sustainable development of the region with an emphasis on the use of natural resource potential is the management of the state of the subsoil and its purpose, with the corresponding maintenance and restoration of the ecological function, ensuring the conflict-free development of the technosphere and biosphere during their development [7]. With regard to the problem of growth the natural resource potential of the region, the implementation of the principles of sustainable development is achieved by resolving the contradiction between the technosphere and biosphere through the possibilities of choosing low-waste, resource-saving and resource-reproducing technologies. The implementation of the principles of improving the environmental friendliness of extractive industries is based on the technologies that ensure both minimization of production waste and the prevention of pollution. Consideration of the environmental factor in ore geotechnology when implementing the concept of sustainable development of the region is a prerequisite for the transition to clean production while realizing its natural resource potential.

\section{Results and Discussion}

In the process of implementing regional natural resource monitoring, the component in the form of natural resources involved in the reproductive development process, is its main information basis. An increase in the level of economic use of the space of nature necessitates obtaining information on the state of the natural resource potential and the extent of its permissible use in economic activity. Moreover, this information should be reliable, which will contribute to increasing the level of environmental security in the region and the effectiveness of the functioning of the natural-economic system. At the same time, the objectivity of information, which reflects the state of the regional natural-economic system, depends on how much the choice of indicators of the economic condition of the region will be characterized by representativeness.

For example, the three different types of human activity are presented in a theoretical model, which the authors consider in order to identify the influence of the natural 
environment on human life. It is argued that such a type of human activity as life activity, which depends on the quality of life and the level of well-being of the population of the regions, determines the nature, degree of intensity and scale of the transforming human impact of man on nature in order to produce material goods. And finally, it is creating a special environment for economic relations between producers, consumers and other economic agents, the main function of which is the transformation of the produced product in numerous processes of social and human economic activity.

Managing the region's natural and economic development based on theoretical models is impossible without using the latest methods of computational mathematics and computer processing of large amounts of data that are implemented through GIS technology. Geoinformation technologies are the technologies of organizing, manipulating, analyzing and presenting various spatial data.

GIS performs several groups of functions: it provides means for the formation of a digital representation of the analyzed objects and phenomena in order to maintain updating, it provides means for editing, updating, storing data, as well as reorganizing and transforming data, it provides analysis, modeling of situations and processes and the integration of heterogeneous information and some other functions.

By combining disparate data into a single form, GIS technology improves the efficiency of managerial decision-making to provide information at various levels of environmental management and natural resource management in specific regions. This will allow economical and efficient use of the natural resource potential of the region, which will increase the competitiveness of the region in modern conditions of an increasing shortage of natural resources.

The development of programs for the sustainable development of the region requires, in our opinion, the attraction of statistical data on the natural and economic condition of the region. In this regard, it is advisable to represent the regional economic system on the basis of interdependent configurations: natural resource and natural economic, which determine the reproduction and development of the region.

In order to manage the natural resource potential of the region, we should, in our opinion, it is necessary to create the regional indicators of the use of resources, due to the peculiarities of the development of the analyzed territories and areas in order to form a possible forecast of the natural resource potential and the development of natural and economic system, and its implementation in natural and economic policy.

The formation of a sustainable type of development in time coincides with the onset of digitalization of production, which assumes, along with information security, environmental safety. Under these conditions, it becomes natural to improve the tools for regulating environmental protection, and changes in the managerial mechanism itself. These may include, firstly, new management principles arising from risk management theory, i.e. transition from a normative approach to environmental management to management based on risk theory. In fact, this means a reorientation of the environmental mechanism to a strategy for managing the quality of the environment, which has replaced a strategy for protecting nature.

It should be noted that the transition to sustainable development of the region is impossible without the processes of institutionalization of environmental management. In accordance with the environmentalization of management, the institutional structure can be considered as a combination of environmental management institutions, forming an integrated system in the context of the ongoing changes.

The institutional structure of environmental management along with administrative regulatory institutions, whose task is to systematize and update the regulatory and methodological base, control measures and direct regulation measures, includes economic institutions whose methods are based on the regulation of financial flows through the 
formation of a system of preferential taxation and credit, subsidizing environmental facilities, countervailing measures, etc. Also an important component of the institutional structure of environmental management are market institutions that formulate the rules of liability, the system of fees and insurance in the field of ecology, and the policy of "bubble principles".

\section{Conclusion}

The current level of environmental safety and the functioning of the regional naturaleconomic system not only determine the preservation of the ecological configuration of the territory, the quality of the natural resource potential and the degree of biological diversity within it, but also contribute to the efficient use of the regional natural resource potential in the future. Based on this, there is a need to consider the environmental configuration as the most important object for monitoring territories. The actualization of the issue of obtaining information about the ecological state and the extent of implementation of the natural and resource potential of the region increases as its level of economic development increases.

\section{References}

1. N. R. Amirova, L. V. Sargina, International Journal of Economic Research, 13:9, 37473757 (2016)

2. E. Dotsenko, N. Ezdina, S. Mudrova, E3S Web Conf., 105, 02008 (2019)

3. G. N. Khadiullina, Mediterranean Journal of Social Sciences, 5:18, 49-53 (2014)

4. O. I. Podurets, Norwegian Journal of development of the International Science, 1:4, 1014 (2017)

5. V. Sirotin, M. Arkhipova, Proceedings of the European Conference on Innovation and Entrepreneurship, ECIE, 673-682 (2015)

6. N. Yu. Sorokina, R. V. Gubarev, N. E. Bondarenko, T. P. Maksimova, Espacios, 39, 27 (2018)

7. V. V. Shlychkov, A. S., Khasanova, I. K. Kiyamov, S. M. Kulish, D. R. Nestulaeva, European Research Studies Journal, 20:2B, 200-223 (2017) 